Article

\title{
Occurrence of Fusarium Mycotoxins in Cereal Crops and Processed Products (Ogi) from Nigeria
}

\author{
Cynthia Adaku Chilaka ${ }^{1,2, *}$, Marthe De Boevre ${ }^{1}$, Olusegun Oladimeji Atanda ${ }^{3}$ \\ and Sarah De Saeger ${ }^{1}$ \\ 1 Laboratory of Food Analysis, Department of Bioanalysis, Faculty of Pharmaceutical Sciences, \\ Ghent University, Ottergemsesteenweg 460, 9000 Ghent, Belgium; marthe.deboevre@ugent.be (M.D.B.); \\ sarah.desaeger@ugent.be (S.D.S.) \\ 2 Department of Food Science and Technology, College of Applied Food Science and Tourism, \\ Michael Okpara University of Agriculture, Umuahia-Ikot Ekpene Road, Umudike, PMB 7267 Umuahia, \\ Abia State, Nigeria \\ 3 Department of Biological Sciences, McPherson University, KM 96 Lagos-Ibadan Expressway, \\ 110117 Seriki Sotayo, Ogun State, Nigeria; olusegunatanda@yahoo.co.uk \\ * Correspondence: cynthia.chilaka@ugent.be; Tel.: +32-9264-8133
}

Academic Editor: HJ (Ine) van der Fels-Klerx

Received: 30 September 2016; Accepted: 13 November 2016; Published: 18 November 2016

\begin{abstract}
In Nigeria, maize, sorghum, and millet are very important cash crops. They are consumed on a daily basis in different processed forms in diverse cultural backgrounds. These crops are prone to fungi infestation, and subsequently may be contaminated with mycotoxins. A total of 363 samples comprising of maize (136), sorghum (110), millet (87), and ogi (30) were collected from randomly selected markets in four agro-ecological zones in Nigeria. Samples were assessed for Fusarium mycotoxins contamination using a multi-mycotoxin liquid chromatography-tandem mass spectrometry (LC-MS/MS) method. Subsequently, some selected samples were analysed for the occurrence of hidden fumonisins. Overall, $64 \%$ of the samples were contaminated with at least one toxin, at the rate of $77 \%, 44 \%, 59 \%$, and $97 \%$ for maize, sorghum, millet, and ogi, respectively. Fumonisins were the most dominant, especially in maize and ogi, occurring at the rate of $65 \%$ and $93 \%$ with mean values of 935 and $1128 \mu \mathrm{g} / \mathrm{kg}$, respectively. The prevalence of diacetoxyscirpenol was observed in maize (13\%), sorghum (18\%), and millet (29\%), irrespective of the agro-ecological zone. Other mycotoxins detected were deoxynivalenol, zearalenone, and their metabolites, nivalenol, fusarenon-X, HT- 2 toxin, and hidden fumonisins. About $43 \%$ of the samples were contaminated with more than one toxin. This study suggests that consumption of cereals and cereal-based products, ogi particularly by infants may be a source of exposure to Fusarium mycotoxins.
\end{abstract}

Keywords: Fusarium mycotoxins; occurrence; cereal; ogi; LC-MS/MS; Nigeria

\section{Introduction}

Mycotoxins are secondary metabolites produced by a wide diversity of toxigenic fungi, which often contaminate crops worldwide [1]. These fungi are ubiquitous in nature, and may contaminate crops in the field or during storage, thus producing mycotoxins under favourable environmental conditions. Fusarium fungi are of high significance because of their ability to cause several devastating plant diseases, and being responsible for economic losses and trade barriers, while having potential in producing a wide range of mycotoxins. Fusarium mycotoxins have been linked to several health related problems in animals and humans ranging from acute (such as anorexia and diarrhoea) to chronic disease conditions (such as cancer and immunosuppression) [2,3]. For instance, fumonisins when ingested are carcinogenic, neurotoxic, and hepatotoxic and may possibly lead to death $[1,2,4]$. Efforts to 
understand the production and behaviour of mycotoxins, and to protect consumers from mycotoxicoses have led to extensive investigation of these toxins across the globe as well as establishment of regulatory maximum limits by the developed countries. Although it is estimated that several Fusarium mycotoxins do exist in nature, those mostly studied are the fumonisins (FB), trichothecenes (TH), and zearalenone (ZEN). This is due to the high toxic effects they exert on humans and animals, and their frequent occurrence in agricultural products especially cereals and cereal-based food products.

Cereals such as maize (Zea mays), sorghum (Sorghum bicolor), and millet (Pennisetum glaucum) serve as major staple crops consumed especially by the middle and low income earners in Nigeria. These crops are often processed into different food forms including processing of traditional weaning meal in the region. Ogi (also known as akamu) is a fermented cereal-based product used as a major traditional weaning food for infants, food for the convalescent and the elderly as well as consumed by different age groups especially as breakfast meal in Nigeria. It is produced by submerge fermentation of cereal grains (maize, sorghum, or millet) for two to three days followed by wet milling and sieving through a mesh. The fermentation process of ogi is usually initiated by chance inoculation under uncontrolled environmental conditions thereby resulting in variable quality of the final product. Studies have reported the prevalence of Fusarium mycotoxins, particularly TH, ZEN, and FB, in cereal crops and cereal-based products globally [5-8]. In most cases, these mycotoxins may co-exist in food and food products which often results to a synergistic, additive or antagonistic toxic effect on the host [9]. The mixed effects of mycotoxins have been revealed by the study of Kouadio et al. [10] on the effects of combinations of $\mathrm{ZEN}$, fumonisin $\mathrm{B}_{1}\left(\mathrm{FB}_{1}\right)$, and deoxynivalenol (DON) on the human intestinal cell line (Caco-2). $\mathrm{FB}_{1}$ in combination with $\mathrm{ZEN}$ showed lesser effect on the reduction of cell viability when compared to the combined effect of $\mathrm{FB}_{1}$ with other mycotoxins because of the antagonistic effect of $\mathrm{FB}_{1}$ on ZEN [10]. Similarly, Speijer and Speijer [9] observed the antagonistic effect of DON on T-2 in the inhibition of human lymphocytes proliferation. It is noteworthy to mention that ternary combination of type B TH (fusarenon-X (FUS-X), nivalenol (NIV), and DON) exhibited an antagonistic interaction on the intestinal epithelial cells which is possibly linked to a lower toxicity of FUS- $X$ in the mixture [11]. There exist a potential relationship in the reduction of FUS- $X$ toxicity and the competition between DON and NIV at the substrate binding sites of the de-acetylase thus leading to a reduced deacetylation of FUS-X [11]. Cases of synergistic interaction exhibited by combination of mycotoxins such as ZEN, DON, and $\mathrm{FB}_{1}$ have also been reported [10,12]. Harvey et al. [13] and Kubena et al. [14] demonstrated the synergistic and additive effects resulting to growth depression in pigs and broiler chicks, respectively because of co-occurrence of mixed mycotoxins (DON and $\left.\mathrm{FB}_{1}\right)$. A synergistic interaction between several combinations of type B TH on epithelial cell toxicity has also been recorded [11,15]. Recently, issues of possible co-existence of these Fusarium mycotoxins and their modified forms have become of great concern. Modification of mycotoxins may be triggered by food processing, or matrix related, or through conjugation by either plant, fungi or animal $[16,17]$. These modified mycotoxins often escape routine analysis leading to underestimation of actual mycotoxin levels in products and may possibly hydrolysed into the parent toxins during digestion [18]. Several studies on the occurrence of Fusarium mycotoxins in cereals and cereal-based products have reported the natural occurrence and co-occurrence of modified mycotoxins such as DON-3-glucoside (DON-3G), ZEN-4-glucoside (ZEN-14G), and $\alpha$ - and $\beta$-zearalenol-4-glucoside ( $\alpha$ - and $\beta$-ZEL-4G) $[5,19]$. The possible underestimation of FB concentration in cereals and cereal-based products as a result of presences of hidden FB has been demonstrated [20-22]. Hidden FB cannot be directly analysed as they have to be released from the matrix into extractable form (hydrolysed FB) by sample treatment often by alkaline hydrolysis $[23,24]$.

The increasing rate of climate change, which is characterised by significant increase or decrease in temperature and/or alteration of rainfall during planting season in sub-Saharan Africa (especially Nigeria), may have predisposed this region to Fusarium mycotoxins contamination. Evidence of possible occurrence of Fusarium mycotoxins in Nigeria is revealed by the frequent incidence of major mycotoxin producing Fusarium species such as F. verticillioides, F. graminearum, F. poae, F. proliferatum, 
and F. sporotrichioides in Nigerian food commodities $[25,26]$. In spite of this obvious evidence, limited study has been undertaken to ascertain the possible occurrence of Fusarium mycotoxins and their modified forms in Nigeria food products. This has resulted to the lack of regulatory maximum levels governing the control of Fusarium mycotoxins in Nigeria. Sub-Saharan African countries including Nigeria solely depend on maximum levels set by the European Union and the Codex Alimentarius Commission on control of Fusarium mycotoxins without considering the feeding habits and other socio-economic dynamics faced by this region. The main objective of the present paper is to investigate the occurrence of Fusarium mycotoxins and their modified forms including fumonisin $\mathrm{B}_{1}, \mathrm{~B}_{2}$, and $\mathrm{B}_{3}$; hidden FB; DON; 3-acetyl-DON (3ADON); 15-acetyl-DON (15ADON); DON-3G; ZEN; $\alpha$-zearalenol ( $\alpha$-ZEL); $\beta$-zearalenol ( $\beta$-ZEL); ZEN-14G; NIV; FUS-X; T-2 toxin (T-2); HT-2 toxin (HT-2); diacetoxyscirpenol (DAS); and neosolaniol (NEO) in Nigerian cereals-maize, sorghum, millet, and the processed products $(\operatorname{og} i)$.

\section{Results and Discussion}

\subsection{Fusarium Mycotoxins Contamination in Cereals (Maize, Sorghum, and Millet) and Processed Products (Ogi) from Nigeria}

A total of 363 samples comprising maize $(n=136)$, sorghum $(n=110)$, millet $(n=87)$, and ogi $(n=30)$ were evaluated for the occurrence of Fusarium mycotoxins and modified forms including $\mathrm{FB}_{1}$, $\mathrm{FB}_{2}, \mathrm{FB}_{3}$, hidden FB, DON, 3ADON, 15ADON, DON-3G, ZEN, $\alpha-Z E L$ and $\beta-Z E L, Z E N-14 G, N I V$, FUS-X, T-2, HT-2, DAS, and NEO. These samples were collected from randomly selected markets from four agro-ecological zones in Nigeria between September 2015 and October 2015. Out of the 18 Fusarium mycotoxins analysed in the samples, 15 toxins were present in at least one of the samples. Data on the incidence and occurrence level of individual Fusarium mycotoxins in the cereals (maize, sorghum, and millet) and processed products (ogi) are illustrated in Tables 1 and 2 . Over $40 \%$ prevalence rate of the mycotoxins was recorded in all sample types, with the individual rate of $77 \%, 44 \%, 59 \%$, and $97 \%$ for maize, sorghum, millet, and ogi, respectively.

Maize, sorghum, millet, and ogi contained 13, 13, 10, and 14 Fusarium secondary metabolites, respectively, of which only four $\left(\mathrm{FB}_{1}, \mathrm{FB}_{2}, \mathrm{DON}\right.$, and $\left.\mathrm{ZEN}\right)$ are regulated by the European Union (EU). Fumonisins were the most dominant mycotoxins occurring at high level and incidence rate in all the food types especially in maize and ogi samples. The sum of fumonisins $\left(\mathrm{FB}_{1}+\mathrm{FB}_{2}+\mathrm{FB}_{3}\right.$ (FB)) were in the ranges of 32-8508 $\mu \mathrm{g} / \mathrm{kg}(65 \%), 45-180 \mu \mathrm{g} / \mathrm{kg}(8 \%), 74-22,064 \mu \mathrm{g} / \mathrm{kg}(14 \%)$, and 125-3557 $\mathrm{\mu g} / \mathrm{kg}(93 \%)$ in maize, sorghum, millet, and ogi, respectively. Except for sorghum, most of the maize and millet samples in this study exceeded the maximum regulatory limit set for the sum of $\mathrm{FB}_{1}$ and $\mathrm{FB}_{2}(1000 \mu \mathrm{g} / \mathrm{kg})$ by the European Union (EU) [27] suggesting the high exposure of the population to this toxin. A similar high FB incidence rate has been reported in several studies from sub-Saharan Africa [28-34] at concentrations ranging up to 53,863 $\mu \mathrm{g} / \mathrm{kg}$ [30]. High incidence of FB, especially in maize may be explained by the susceptibility of the maize crop to FB producing fungi (F. verticillioides and F. proliferatum) [35]. Sorghum and millet had a much lower incidence rate, however an extreme concentration of FB was recorded in one of the millet samples $(22,064 \mu \mathrm{g} / \mathrm{kg})$. Lower concentrations and incidence rate in sorghum and millet from Ethiopia have previously been reported [36]. However, the reversed trend was observed by Ayalew et al. [37], who recorded higher levels of FB (range: 1370-2117 $\mu \mathrm{g} / \mathrm{kg}$ ) in sorghum samples. Of the FB, $\mathrm{FB}_{1}$ occurred at a more frequent rate than $\mathrm{FB}_{2}$ and $\mathrm{FB}_{3}$. Although, we observed that some of the millet $(n=4)$ and maize $(n=16)$ samples were contaminated with only $\mathrm{FB}_{2}$. Such trend has previously been reported in cereals suggesting the possible contamination of Aspergillus niger, which is a principal producer of $\mathrm{FB}_{2}$ [38]. The study of Ezekiel et al. [39] on sorghum grain confirms the possible occurrence of only $\mathrm{FB}_{2}$ in cereals from Nigeria. The incidence and levels of FB as observed in ogi is of concern. This present study reveals for the first time the occurrence of Fusarium mycotoxins in ogi from Nigerian market. The maximum concentration and percentage incidence of $\mathrm{FB}_{1}, \mathrm{FB}_{2}$, and $\mathrm{FB}_{3}$ detected in ogi samples were $1903 \mu \mathrm{g} / \mathrm{kg}$ (93\%), 1,283 $\mu \mathrm{g} / \mathrm{kg}(87 \%)$, and $371 \mu \mathrm{g} / \mathrm{kg}(77 \%)$, respectively (Table 1). About $83 \%$ of the ogi samples 
exceeded the EU maximum limit of $200 \mu \mathrm{g} / \mathrm{kg}$ for processed maize-based foods for infants and young children [27]. Interestingly, out of the 30 ogi samples analysed, the only two FB negative samples were of sorghum-base. This confirms the previous study that sorghum is less prone to fungal infestation than maize [39]. Although there are no available data on the occurrence of Fusarium mycotoxins in ogi, studies from the same country reported the occurrence of FB in two fermented traditional cereal-based beverages (kunu-zaki and pito) [39].

The next group of dominating mycotoxins were the TH. They have been associated with the temperate regions, however studies emerging from sub-Saharan Africa have revealed the possible occurrence of these toxins in the tropics. Type B TH DON, 15ADON, DON-3G, and NIV were detected in our samples. DON was present in $16 \%, 3 \%, 13 \%$, and $13 \%$ of maize, sorghum, millet, and ogi samples at a maximum level of $225 \mu \mathrm{g} / \mathrm{kg}, 119 \mu \mathrm{g} / \mathrm{kg}, 583 \mu \mathrm{g} / \mathrm{kg}$, and $74 \mu \mathrm{g} / \mathrm{kg}$, respectively. Interestingly no sample, irrespective of the food type, exceeded the EU maximum limit $(1750 \mu \mathrm{g} / \mathrm{kg}$, maize; $1250 \mu \mathrm{g} / \mathrm{kg}$, other cereals; and $200 \mu \mathrm{g} / \mathrm{kg}$, cereal-based infant foods) for DON [27]. Incidence of DON, as observed in this study, was similar to that reported in previous studies on Nigerian cereals [26,40], but much less than that reported in maize by Adetunji et al. [32] and Ediage et al. [34]. The same trend was reported in millet, sorghum, and cereal-based food samples from Burkina Faso [29]. Studies have shown the occurrence of acetylated DON forms and DON-3G in maize and its products [31,41]. Maize samples in our study were negative for 3ADON, 15ADON, and DON-3G. This is in agreement with a previous study on maize from Burkina Faso [29]. Sorghum, millet, and ogi were contaminated with 15ADON, and were negative of 3ADON. The production of acetylated derivatives (15ADON and 3ADON) by F. graminearum have been reported and the potential of the isolates to produce 15ADON or 3ADON as the major isomer is dependent on the geographic origin [42,43]. Although the information on the regional relationship between $F$. graminearum and the production of 15ADON or 3ADON is still lacking in Africa, Li et al. [44] and Mirocha et al. [42] reported the predominant of 3ADON in New Zealand, Austrialia, and China while 15ADON chemotype is predominant in North America. The glucoside of DON (DON-3G) was observed to contaminate sorghum and ogi samples in the present study. A comparable result on DON-3G in sorghum and millet from Ethiopia have also been reported [36].

Samples of maize $(n=3)$ and ogi $(n=2)$ were contaminated with NIV at concentration ranges of 163-271 $\mu \mathrm{g} / \mathrm{kg}$ and 136-160 $\mu \mathrm{g} / \mathrm{kg}$, respectively. Occurrence of NIV in Nigerian maize has previously been reported, although at a higher incidence rate (54\%) [32]. While similar result in cereal-based products as shown in this study was reported by Castillo et al. [45]. Contrary to the result reported on the occurrence of NIV in sorghum and millet by Chala et al. [36], sorghum and millet were negative for NIV in the present study. The trend observed in this study with NIV was also seen with FUS-X contamination. NEO was not detected in any of the samples analysed.

With regards to type A TH, DAS and HT-2 were present in all the sample types except for the cereal-based products (ogi) which was negative for DAS, while T-2 was negative in all the sample types. DAS was detected in maize, sorghum, and millet at a rate of $13 \%, 18 \%$, and $29 \%$, respectively (Table 1). The concentrations of DAS in the cereals ranged between $2 \mu \mathrm{g} / \mathrm{kg}$ and $25 \mu \mathrm{g} / \mathrm{kg}$. The occurrence of DAS in the samples is probably associated with the occurrence of major DAS-producing fungi in this region $[25,26]$. DAS and HT-2 are synthesised by a wide range of Fusarium species, and they are alleged to be among the most toxic TH occurring in different food products. Several studies have reported the occurrence of DAS in cereals and cereal-based products $[46,47]$. Despite its association with the temperate weather, previous studies revealed the occurrence of DAS in the tropical regions. Adejumo et al. [26] and Adetunji et al. [32] recorded the occurrence of DAS in Nigerian maize at maximum concentrations of $51 \mu \mathrm{g} / \mathrm{kg}(9 \%)$ and $30 \mu \mathrm{g} / \mathrm{kg}(19 \%)$, respectively . Besides maize, DAS has been found to contaminate sorghum and millet from Ethiopia with maximum concentrations of $64.2 \mu \mathrm{g} / \mathrm{kg}$ (mean value, $11.9 \mu \mathrm{g} / \mathrm{kg}$ ), and $1.43 \mu \mathrm{g} / \mathrm{kg}$ (mean value, $1.43 \mu \mathrm{g} / \mathrm{kg}$ ), respectively [36]. A total of $1 \%, 8 \%, 5 \%$, and $3 \%$ of maize, sorghum, millet, and ogi, respectively, were positive of HT-2 (Table 1). Beside the low incidence rate, none of the cereals or ogi samples exceeded the EU recommendation level of $100 \mu \mathrm{g} / \mathrm{kg}$ and $15 \mu \mathrm{g} / \mathrm{kg}$ for cereal and infant foods, respectively [48]. 
Table 1. Mean and maximum concentration $(\mu \mathrm{g} / \mathrm{kg})$ of Fusarium mycotoxins found in cereals and cereal-based products (ogi) from Nigeria.

\begin{tabular}{|c|c|c|c|c|c|c|c|c|c|c|c|c|}
\hline \multirow{2}{*}{ Mycotoxin $^{1}$} & \multicolumn{3}{|c|}{ Maize $(n=136)$} & \multicolumn{3}{|c|}{ Sorghum $(n=110)$} & \multicolumn{3}{|c|}{ Millet $(n=87)$} & \multicolumn{3}{|c|}{$O g i(n=30)$} \\
\hline & $\%$ + ve Samples ${ }^{2}$ & Mean $^{3}$ & $\operatorname{Max}^{4}$ & $\%$ + ve Samples & Mean & Max & $\%$ + ve Samples & Mean & Max & $\%$ + ve Samples & Mean & Max \\
\hline $\mathrm{FB}_{1}$ & 65 & 541 & 8222 & 8 & 64 & 78 & 9 & 2333 & 18,172 & 93 & 590 & 1903 \\
\hline $\mathrm{FB}_{2}$ & 54 & 376 & 2885 & 2 & 48 & 55 & 13 & 609 & 3892 & 87 & 472 & 1283 \\
\hline $\mathrm{FB}_{3}$ & 43 & 117 & 445 & 2 & 38 & 46 & 0 & na & na & 77 & 121 & 371 \\
\hline$\sum \mathrm{FB}$ & 65 & 935 & 8508 & 8 & 83 & 180 & 14 & 2113 & 22,064 & 93 & 1128 & 3557 \\
\hline$\overline{\mathrm{DON}}$ & 16 & 99 & 225 & 3 & 100 & 119 & 13 & 151 & 543 & 13 & 61 & 74 \\
\hline $15 \mathrm{ADON}$ & 0 & na $^{5}$ & na & 2 & 39 & 44 & 1 & 11 & 11 & 3 & 60 & 60 \\
\hline DON-3G & 0 & na & na & 23 & 24 & 63 & 0 & na & na & 17 & 30 & 44 \\
\hline ZEN & 1 & 65 & 65 & 1 & 38 & 38 & 14 & 419 & 1399 & 3 & 39 & 39 \\
\hline ZEN-14G & 9 & 21 & 24 & 3 & 19 & 22 & 6 & 23 & 34 & 3 & 31 & 31 \\
\hline$\alpha-Z E L$ & 1 & 20 & 20 & 3 & 33 & 33 & 0 & na & na & 7 & 20 & 22 \\
\hline$\beta$-ZEL & 2 & 20 & 21 & 1 & 21 & 21 & 1 & 39 & 39 & 10 & 19 & 20 \\
\hline HT-2 & 1 & 20 & 20 & 8 & 20 & 31 & 5 & 36 & 36 & 3 & 13 & 13 \\
\hline NIV & 2 & 206 & 271 & 0 & na & na & 0 & na & na & 7 & 148 & 160 \\
\hline FUS-X & 1 & 154 & 154 & 0 & na & na & 0 & na & na & 7 & 133 & 137 \\
\hline DAS & 13 & 3 & 8 & 18 & 5 & 16 & 29 & 5 & 25 & 0 & na & na \\
\hline
\end{tabular}

${ }^{1} \mathrm{FB}_{1}, \mathrm{~B}_{2}$, and $\mathrm{B}_{3}=$ fumonisin $\mathrm{B}_{1}, \mathrm{~B}_{2}$ and $\mathrm{B}_{3} ; \sum \mathrm{FB}=$ sum of $\mathrm{FB}_{1}, \mathrm{~B}_{2}$, and $\mathrm{B}_{3} ; \mathrm{DON}=$ deoxynivalenol; $15 \mathrm{ADON}$ = 15-acetyl-deoxynivalenol; $\mathrm{DON}-3 \mathrm{G}=$ deoxynivalenol-3-glucoside

$\mathrm{ZEN}=$ zearalenone; $\alpha$-ZEL $=\alpha$-zearalenol; $\beta$-ZEL $=\beta$-zearalenol; ZEN-14G = zearalenone-14-glucoside; NIV = nivalenol; FUS-X $=$ fusarenon-X; HT- $2=\mathrm{HT}-2$ toxin; DAS $=$ diacetoxyscirpenol, ${ }^{2} \%+$ ve Samples $=$ percentage positive samples, ${ }^{3}$ Mean $=$ mean concentration, ${ }^{4}$ Max $=$ maximum concentration, ${ }^{5}$ na $=$ not applicable. 
Table 2. Contamination levels of fumonisins, total fumonisins, and hidden fumonisin in selected samples.

\begin{tabular}{cccccccccc}
\hline \multirow{2}{*}{ Food Type } & \multicolumn{3}{c}{ FB $(\mu \mathrm{g} / \mathbf{k g})$} & \multicolumn{3}{c}{ Total FB $(\mu \mathrm{g} / \mathbf{k g})$} & \multicolumn{3}{c}{ Hidden FB $(\boldsymbol{\mu g} / \mathbf{k g})$} \\
\cline { 2 - 9 } & Median & Mean & Maximum & Median & Mean & Maximum & Median & Mean & Maximum \\
\hline Maize $(n=10)$ & 358 & 835 & 3514 & 543 & 1636 & 4568 & 144 & 801 & 2923 \\
Sorghum $(n=10)$ & 41 & 61 & 180 & 95 & 182 & 502 & 50 & 120 & 323 \\
Millet $(n=10)$ & 118 & 277 & 840 & 302 & 776 & 3059 & 179 & 499 & 2254 \\
Ogi $(n=10)$ & 247 & 531 & 1496 & 391 & 672 & 1795 & 117 & 141 & 313 \\
\hline
\end{tabular}

Hidden FB concentration = the difference between the concentration of FB and the concentration of total FB after hydrolysis.

Other mycotoxins detected in the study include ZEN, $\alpha$-ZEL, $\beta$-ZEL, and ZEN-14G. Recent studies have shown the prevalence of ZEN in food products from sub-Saharan Africa [36,49], however in the present study, ZEN was rarely detected. ZEN was detected in maize, sorghum, and millet at $1 \%, 1 \%$, and $14 \%$, respectively (Table 1 ) with the concentrations in all the sample types being less than the EU maximum limit of ZEN, except for millet with 8 samples (9\%) exceeding $100 \mu \mathrm{g} / \mathrm{kg}$ [27]. Further, only one sample (3\%) of ogi was positive for ZEN with the value exceeding the maximum limit of $20 \mu \mathrm{g} / \mathrm{kg}$ set by EU for processed cereal-based foods for infants and young children [50]. About $1 \%$ and $2 \%$ of maize were contaminated with $\alpha$-ZEL and $\beta$-ZEL, respectively. Although there exist only limited studies on the occurrence of these metabolites in food products from sub-Saharan Africa, available data show their possible occurrence in Nigerian maize [32,49]. The present study is in agreement with the result of Adetunji et al. [32]. The maximum levels for $\beta$-ZEL in sorghum, millet, and ogi were $21 \mu \mathrm{g} / \mathrm{kg}, 39 \mu \mathrm{g} / \mathrm{kg}$, and $20 \mu \mathrm{g} / \mathrm{kg}$, respectively. Millet samples were negative of $\alpha$-ZEL while sorghum and ogi had 3\% and 7\% incidence rate with maximum levels of $33 \mu \mathrm{g} / \mathrm{kg}$ and $22 \mu \mathrm{g} / \mathrm{kg}$, respectively (Table 1). Chala et al. [36] reported a higher incidence rate of $\alpha$-ZEL and $\beta$-ZEL in sorghum and millet compared to the current study, however, the levels reported by these authors were lower. With regards to ZEN-14G, all food type samples analysed showed positive samples with maximum concentrations of $24 \mu \mathrm{g} / \mathrm{kg}$ (maize), $22 \mu \mathrm{g} / \mathrm{kg}$ (sorghum), $34 \mu \mathrm{g} / \mathrm{kg}$ (millet), and $31 \mu \mathrm{g} / \mathrm{kg}$ (ogi). Occurrence of this modified form of ZEN in cereals and ogi in the current study is supported by a study which detected a wide range of modified forms of ZEN in cereal-based food products $[18,19]$. Although, there are no recommendation nor regulation limit of ZEN-14G in cereals and cereal-based products because of the non availability of toxicological data, the occurrence of ZEN-14G as observed in the present study is presumed to add additional toxic effect to the host. De Boevre et al. [51] reported the possible hydrolysis of ZEN-14G into its parent form (ZEN) in the digestive tract of mammals suggesting an additional toxicity.

\subsection{Fumonisins and Hidden Fumonisins Contamination in Cereals (Maize, Sorghum and Millet) and Processed} Products (Ogi) from Nigeria

To determine the occurrence of hidden fumonisins, samples were selected from each food type based on the FB result obtained from the multi-mycotoxin analysis (Table 1). Five FB positive and five FB negative samples of each food type (maize, sorghum, and millet) were selected for analysis. Note that eight positive samples and two negative samples of ogi were used for the analysis because only two samples of ogi were negative. Each of the samples were analysed simultaneously for FB $\left(\mathrm{FB}_{1}, \mathrm{FB}_{2}\right.$, and $\left.\mathrm{FB}_{3}\right)$ as well as total fumonisins after hydrolysis as described in Section 4. Calculation of hidden FB concentration was based on the difference between the concentration of FB and the concentration of total FB after hydrolysis [52]. The maximum FB and total FB concentration in the selected samples of maize, sorghum, millet, and ogi samples were 3514 and $4568 \mu \mathrm{g} / \mathrm{kg}, 180$ and $502 \mu \mathrm{g} / \mathrm{kg}, 840$ and $3059 \mu \mathrm{g} / \mathrm{kg}$, and 1496 and $1795 \mu \mathrm{g} / \mathrm{kg}$, respectively. After hydrolysis, we observed an increment ranging from 1.3 to 5.2 times higher levels of total FB in maize samples. The same trend was observed in sorghum, millet, and ogi samples. Hidden FB have been alleged to occur in processed products especially nixtamalised and thermally processed foods [52,53]. However, recent 
studies have revealed the occurrence of these toxins in unprocessed food products especially in raw maize samples $[20,54]$ which suggest the possible transformation of FB to bound derivatives by natural phenomena due to plant metabolism [24]. The presence of hidden FB as observed in the current study may pose an additional health risk to consumers especially to the consumers of ogi analysed in this study. FB has been alleged to cause a range of toxic health effect on humans and animals especially in sub-Saharan Africa where cases of very high levels of FB have been recorded. Cases of human oesophageal cancer in South Africa and other parts of the World have been linked to the consumption of food contaminated with FB. Since it is obvious that hidden FB may cause additional toxic effect on the host as observed when low FB contaminated feed was fed to animals [55], the occurrence of hidden FB in cereals and cereal-based products should no longer be neglected especially in Nigeria where these products serve as major staple food.

\subsection{Distribution of Fusarium Mycotoxins in Major Cereals across the Different Agro-Ecological Zones of Nigeria}

Mycotoxin occurrence and distribution is influenced by different factors including crop species, climatic, and environmental conditions of a given region. The mean and maximum concentrations of individual mycotoxins in the different food types and AEZ are shown in Table 3. Fumonisins contaminations were observed in all the cereal types irrespective of the AEZ. Sudan Savanna (SS) and Northern Guinea Savanna (NGS) zones had the highest incidence rate of $\mathrm{FB}_{1}$ in maize with a highest $\mathrm{FB}_{1}$ concentration of $2443 \mu \mathrm{g} / \mathrm{kg}$ and $8222 \mu \mathrm{g} / \mathrm{kg}$, respectively, when compared to Southern Guinea Savanna (SGS) and Derived Savanna (DS). A similar trend with $\mathrm{FB}_{1}$ contamination was also seen when the sum of $\mathrm{FB}\left(\mathrm{FB}_{1}, \mathrm{FB}_{2}\right.$, and $\left.\mathrm{FB}_{3}\right)$ was considered. This is also similar with the result obtained from the sorghum samples, with the SS zone registering the highest $\mathrm{FB}_{1}$ followed by NGS and SGS. This observation could be linked to the high mycotoxins production potentials of Fusarium fungi in warmer climates [56] and the significant change in climatic conditions in this region characterised by increase in rainfall and longer raining seasons [57]. Among the other mycotoxins detected, DAS was the next most common metabolite contaminating all the food types across the AEZ, although at lower concentrations. While there are no existing regulatory limits set for DAS in food products, DAS has been implicated in a wide range of toxic effects in animals as well as human, ranging from acute to chronic. It has been linked to a human fatal disease (alimentary toxic aleukia), exhibiting several symptoms such as inflammation of the skin, vomiting, and damage to hematopoietic tissues [1,3]. DON also occurred in the respective cereal types across the AEZ, except for the sorghum samples from the SGS zone (Table 3). The highest incidence rate of DON was observed in maize samples from DS zone characterized by a lower temperature and higher average annual rainfall of $25-35^{\circ} \mathrm{C}$ and $1300-1500 \mathrm{~mm}$, respectively when compared to the other zones. In millet samples, the NGS zone registered the highest incidence rate of DON. Comparing the incidence of ZEN across the different food types and AEZ, samples from SS zones were negative of ZEN regardless of the cereal type. This result could be related to the prevailing local weather conditions of this region which is between 30 and $40{ }^{\circ} \mathrm{C}$, which is above the optimum temperature of $25^{\circ} \mathrm{C}$ for the production of ZEN [58].

In general, it is postulated that Fusarium fungi and subsequent mycotoxins occurrence is higher in colder regions. We observed the trend in the incidence of Fusarium toxins in this study with approximately colder region having multiple mycotoxins (Table 3). Further analysis to assess the significant difference in the distribution of Fusarium mycotoxins across the AEZ was done using the Kruskal Wallis test (Figure 1). With respect to maize, there was a significant difference in $\mathrm{FB}_{1}$ and DAS contamination across the AEZ, whereas in millet samples, DAS contamination was significantly different across the different zones. The less difference observed across the AEZ in the current study may be attributed to the quality of the sampled food products because of the premium placed on high quality (visual observation) food products which arises through sorting and cleaning in order to add more value to the products, thus increasing the market value of the food product. 
Table 3. Fusarium mycotoxins occurrence in cereals (maize, sorghum, and millet) across the different agro ecological zones of Nigeria.

\begin{tabular}{|c|c|c|c|c|c|c|c|c|c|c|c|c|c|c|c|c|c|c|c|c|}
\hline \multirow{3}{*}{ Mycotoxin $^{1}$} & \multicolumn{8}{|c|}{ Maize $(\mu \mathrm{g} / \mathrm{kg})$} & \multicolumn{6}{|c|}{ Sorghum ( $\mu \mathrm{g} / \mathbf{k g})$} & \multicolumn{6}{|c|}{ Millet $(\mu \mathrm{g} / \mathrm{kg})$} \\
\hline & \multicolumn{2}{|c|}{ DS $(n=30)$} & \multicolumn{2}{|c|}{$\operatorname{SGS}(n=36)$} & \multicolumn{2}{|c|}{ NGS $(n=40)$} & \multicolumn{2}{|c|}{ SS $(n=30)$} & \multicolumn{2}{|c|}{ SGS $(n=30)$} & \multicolumn{2}{|c|}{ NGS $(n=40)$} & \multicolumn{2}{|c|}{ SS $(n=40)$} & \multicolumn{2}{|c|}{ SGS $(n=30)$} & \multicolumn{2}{|c|}{ NGS $(n=30)$} & \multicolumn{2}{|c|}{ SS $(n=27)$} \\
\hline & $\begin{array}{c}\text { Mean }{ }^{2}(\%+ \\
\text { ve) })^{3}\end{array}$ & $\operatorname{Max}^{4}$ & $\begin{array}{c}\text { Mean (\% } \\
+ \text { ve) }\end{array}$ & $\operatorname{Max}$ & $\begin{array}{c}\text { Mean (\% + } \\
\text { ve) }\end{array}$ & $\operatorname{Max}$ & $\begin{array}{c}\text { Mean (\% + } \\
\text { ve) }\end{array}$ & $\operatorname{Max}$ & $\begin{array}{c}\text { Mean }(\%+ \\
\text { ve) }\end{array}$ & $\operatorname{Max}$ & $\begin{array}{c}\text { Mean (\% + } \\
\text { ve) }\end{array}$ & $\operatorname{Max}$ & $\begin{array}{c}\text { Mean }(\%+ \\
\text { ve) }\end{array}$ & Max & $\begin{array}{c}\text { Mean (\% + } \\
\text { ve) }\end{array}$ & $\operatorname{Max}$ & $\begin{array}{c}\text { Mean (\% + } \\
\text { ve) }\end{array}$ & Max & $\begin{array}{c}\text { Mean (\% + } \\
\text { ve) }\end{array}$ & Max \\
\hline $\mathrm{FB}_{1}$ & $117(67)$ & 366 & $249(33)$ & 876 & $928(83)$ & 8222 & $505(77)$ & 2443 & $70(7)$ & 71 & 59 (10) & 76 & $67(8)$ & 78 & 3700 (17) & 18,172 & $54(10)$ & 84 & na & na \\
\hline $\mathrm{FB}_{2}$ & $289(57)$ & 1011 & $350(28)$ & 677 & $508(65)$ & 2885 & $295(70)$ & 1107 & na & na & $41(3)$ & 41 & $55(3)$ & 55 & $417(37)$ & 3892 & $56(13)$ & 103 & $44(7)$ & 47 \\
\hline $\mathrm{FB}_{3}$ & $114(47)$ & 353 & $147(25)$ & 445 & $126(53)$ & 441 & $91(50)$ & 213 & na & na & $31(3)$ & 31 & $46(3)$ & 46 & na & na & na & na & na & na \\
\hline DON & $78(27)$ & 147 & $99(17)$ & 180 & $98(10)$ & 151 & $140(13)$ & 225 & $119(3)$ & 119 & 91 (5) & 92 & na & na & $140(7)$ & 200 & $171(20)$ & 543 & $118(11)$ & 118 \\
\hline 15 ADON & na ${ }^{5}$ & na & na & na & na & na & na & na & $34(3)$ & 34 & $44(3)$ & 44 & na & na & na & na & na & na & $11(4)$ & 11 \\
\hline DON-3G & na & na & na & na & na & na & na & na & $12(27)$ & 16 & $30(40)$ & 63 & $22(3)$ & 22 & na & na & na & na & na & na \\
\hline ZEN & na & na & na & na & $65(3)$ & 65 & na & na & $38(3)$ & 38 & na & na & na & na & 481 (33) & 1399 & 109 (7) & 198 & na & na \\
\hline ZEN-14G & $20(23)$ & 24 & $21(6)$ & 22 & $23(8)$ & 23 & na & na & 20 (3) & 20 & $19(5)$ & 22 & na & na & $29(7)$ & 34 & $19(7)$ & 20 & $23(4)$ & 23 \\
\hline$\alpha-Z E L$ & na & na & $20(3)$ & 20 & na & na & na & na & na & na & $33(8)$ & 33 & na & na & na & na & na & na & na & na \\
\hline$\beta$-ZEL & 20 (3) & 20 & na & na & 21 (3) & 21 & na & na & 21 (3) & 21 & na & na & na & na & na & na & 39 & 39 & na & na \\
\hline HT-2 & $20(3)$ & 20 & na & na & na & na & na & na & 19 (17) & 19 & $24(8)$ & 31 & 11 (3) & 11 & $35(7)$ & 35 & $36(7)$ & 36 & na & na \\
\hline NIV & $228(7)$ & 271 & na & na & na & na & $163(3)$ & 163 & na & na & na & na & na & na & na & na & na & na & na & na \\
\hline FUS-X & 154 (3) & 154 & na & na & na & na & na & na & na & na & na & na & na & na & na & na & na & na & na & na \\
\hline DAS & $2(10)$ & 2 & $3(17)$ & 6 & $3(18)$ & 4 & $8(7)$ & 8 & $5(27)$ & 13 & $4(13)$ & 5 & $5(18)$ & 16 & $12(17)$ & 25 & $4(37)$ & 6 & $3(33)$ & 4 \\
\hline
\end{tabular}

Abbreviation: DS = Derived Savanna; SGS = Southern Guinea Savanna; NGS = Northern Guinea Savanna; SS = Sudan Savanna. ${ }^{1} \mathrm{FB}_{1}, \mathrm{~B}_{2}$, and $\mathrm{B}_{3}=$ fumonisin $\mathrm{B}_{1}, \mathrm{~B}_{2}$, and $\mathrm{B}_{3} ; \mathrm{DON}=$ deoxynivalenol; $15 \mathrm{ADON}=15$-acetyl-deoxynivalenol; DON-3G = deoxynivalenol-3-glucoside; $\mathrm{ZEN}=$ zearalenone; $\alpha$-ZEL $=\alpha$-zearalenol; $\beta$-ZEL $=\beta$-zearalenol; ZEN-14G = zearalenone-14-glucoside; NIV = nivalenol; FUS-X = fusarenon-X; HT-2 = HT-2 toxin; DAS = diacetoxyscirpenol; ${ }^{2}$ Mean $=$ mean concentration, ${ }^{3} \%+$ ve $=$ percentage positive samples, ${ }^{4}$ Max $=$ maximum concentration, ${ }^{5}$ na $=$ not applicable. 
$\mathbf{a}$
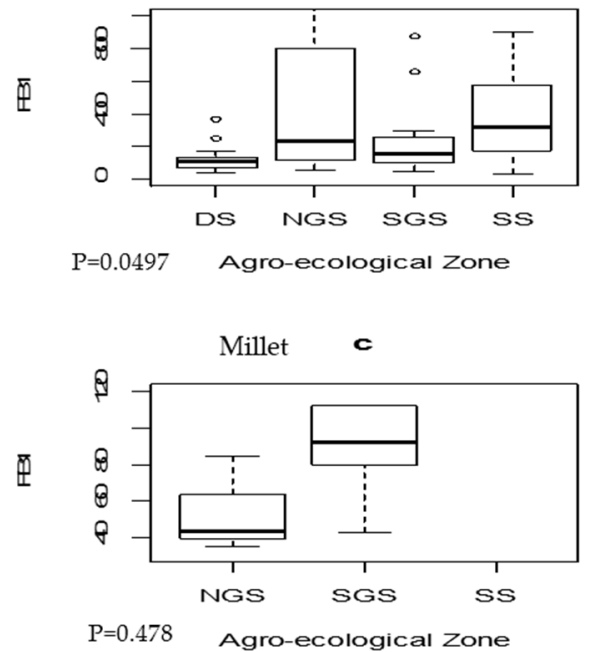

b

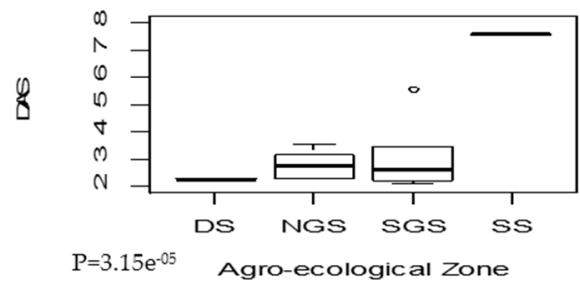

d

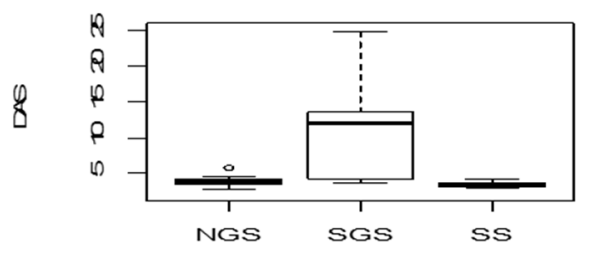

$\mathrm{P}=0.00122$ Agro-ecological Zone

Figure 1. Differences in Fusarium mycotoxins in maize ((a) fumonisin $\mathrm{B}_{1}$; and (b) diacetoxyscirpenol); and millet ((c) fumonisin $\mathrm{B}_{1}$; and (d) diacetoxyscirpenol) across agro-ecological zones.

\subsection{Co-Occurrence of Fusarium Mycotoxins in Cereals and Processed Products (Ogi) from Nigeria}

Occurrence of multiple mycotoxins in food, especially cereals and cereal-based products has been an issue of great concern because of the synergistic and/or additive effects caused by the interaction of these toxins in humans and animals. In this study, we observed that $60 \%, 19 \%, 30 \%$, and $93 \%$ of maize, sorghum, millet, and ogi, respectively, were contaminated with at least two mycotoxins (Figure 2). In maize samples, FB co-existed with DAS at 13\%, being the highest level observed, followed by co-occurrence between FB and DON (11\%). DAS and DON-3G co-occurred in 16\% of sorghum samples, succeeded by DON-3G and HT2, while DAS and ZEN dominated in millet samples followed by DAS and DON. Previous studies have shown the frequent co-contamination of Fusarium toxins in cereal products in sub-Saharan Africa [32,34,36], which is linked to co-occurrence of several species of Fusarium fungi in crops or the potential ability of one Fusarium spp. to produce more than one mycotoxins [59]. However, the rates observed in sorghum and millet in the present study were in contrast with the data reported on co-occurrence of mycotoxins in sorghum $(94 \%)$ and millet $(85 \%)$ from South Korean retail markets [60], and may be attributed to the different sampling regions considered for these studies.

Although only limited studies exist on the co-occurrence of DON, ZEN, and their modified forms in sub-Saharan Africa, available data proves the potential of DON co-occurring with its modified forms in cereals from this region [34]. This was not the case in this study. The disparity may be attributed to the differences in sampling protocol. Ediage et al. [34] analysed household samples, while samples from the markets were analysed in the present study. Cereals purchased from the market often are of better quality compared to those from the household or at farmers disposal. Ironically, this is because high-graded cereal grains are often placed for sale by the farmers because of a better market bargain, while they retain the poor quality cereal grains since there are no provisional channels for destruction or diversion of these products.

Interestingly, the processed cereal-based products (ogi) analysed in this study had the highest co-occurrence rate compared to the cereals. This observation could be attributed to many factors (such as poor sanitation during processing). Ogi is fermented under uncontrolled conditions, and as such could be contaminated with any form of organism residing in the environment. Another possible avenue for contamination is the quality of the raw cereal used in the production of ogi. Although reduction of mycotoxin concentrations have been reported during processing of ogi [61], it is important to mention that reduction of mycotoxins during food processing is dependent on the 
initial concentrations of the raw produce and as such good quality cereal grains should be used for production of ogi. Up to $23 \%$ of ogi samples were contaminated with at least five mycotoxins, with the highest co-occurrence existing between FB and DON-3G, and subsequently between FB and DON. DON and DON-3G co-occurred in four of the samples while ZEN, ZEN-14G, $\alpha$-ZEL, and $\beta$-ZEL co-occurred in one sample. This result is affirmed by the previous study on co-occurrence of these metabolites in cereal-based products [5]. However, the rates and concentration levels in their study were higher than the levels observed in this study.

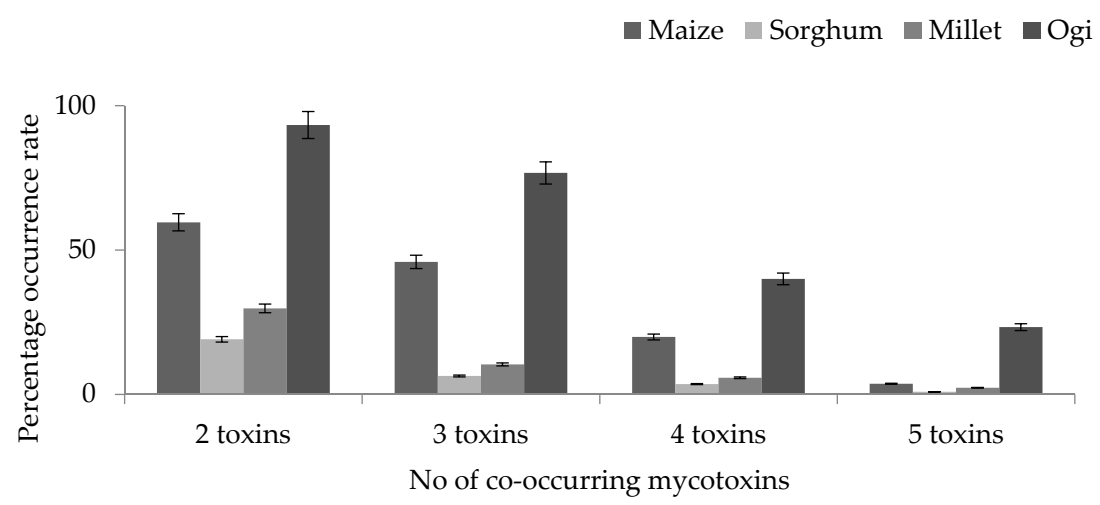

Figure 2. Percentage of co-occurrence of Fusarium mycotoxins in maize, sorghum, millet, and ogi from Nigerian markets.

\section{Conclusions}

The present study showed the occurrence of Fusarium toxins in cereals and cereal-based fermented products (ogi) in Nigeria. Fumonisins were the most dominating Fusarium mycotoxins with some of the samples exceeding the FB regulatory limits set by the EU. Although the levels of other mycotoxins detected in the samples were low, the co-occurrence of these mycotoxins presents a health risk due to the synergistic and/or additive effect, considering the fact that these food products are consumed almost on daily basis. In addition, it is worrisome that the traditional weaning food fed to a large population of infant and growing children in this region contains high levels of FB with a cocktail of other mycotoxins. This phenomenon shows that infants are affected with different variation of toxic effects. Reducing mycotoxins in ogi is important, and mainly determined by the quality of the raw cereal before fermentation. Therefore, there is need to educate the small-scale producers on the risk of mycotoxins and possible ways to reduce or avoid contamination. Furthermore, it is worth mentioning that though all cereals were contaminated with varying degrees of toxins, the incidence rate was higher in maize, suggesting sorghum and millet as a possible alternative. These results suggest the need for a national coordinated food safety action plan.

\section{Materials and Methods}

\subsection{Sampling}

Nigeria has seven agro-ecological zones (AEZ) (Figure 3) based on the climatic and environmental conditions, out of which four AEZ were selected for sampling which include the Derived Savanna (DS), Southern Guinea Savanna (SGS), Northern Guinea Savanna (NGS), and Sudan Savanna (SS). The sampling sites were considered on the production areas of the crops and products. One state from each AEZ was covered for each crop and product. Maize samples were collected from four AEZ while millet and sorghum were sampled from SGS, NGS, and SS; and ogi samples were collected from DS. Table 4 shows the detailed sampling sites.

The geographical location, temperature, and rainfall pattern of DS, SGS, NGS, and SS are documented by Udoh et al. and Atehnkeng et al. [62,63]. Briefly, the DS is characterized by an 
annual rainfall distribution and temperature ranging between $1300 \mathrm{~mm}$ and $1500 \mathrm{~mm}$, and $25^{\circ} \mathrm{C}$ to $35^{\circ} \mathrm{C}$, respectively. The average annual rainfall of SGS is between $1000 \mathrm{~mm}$ and $1300 \mathrm{~mm}$ with a temperature range of 26 to $38^{\circ} \mathrm{C}$. The NGS has rainfall distribution averaging between $900 \mathrm{~mm}$ and $1000 \mathrm{~mm}$ annually, and temperatures vary from 28 to $40{ }^{\circ} \mathrm{C}$, while SS is characterised by an annual rainfall distribution between $650 \mathrm{~mm}$ and $1000 \mathrm{~mm}$ annually, and temperatures varying from 30 to $40{ }^{\circ} \mathrm{C}$.

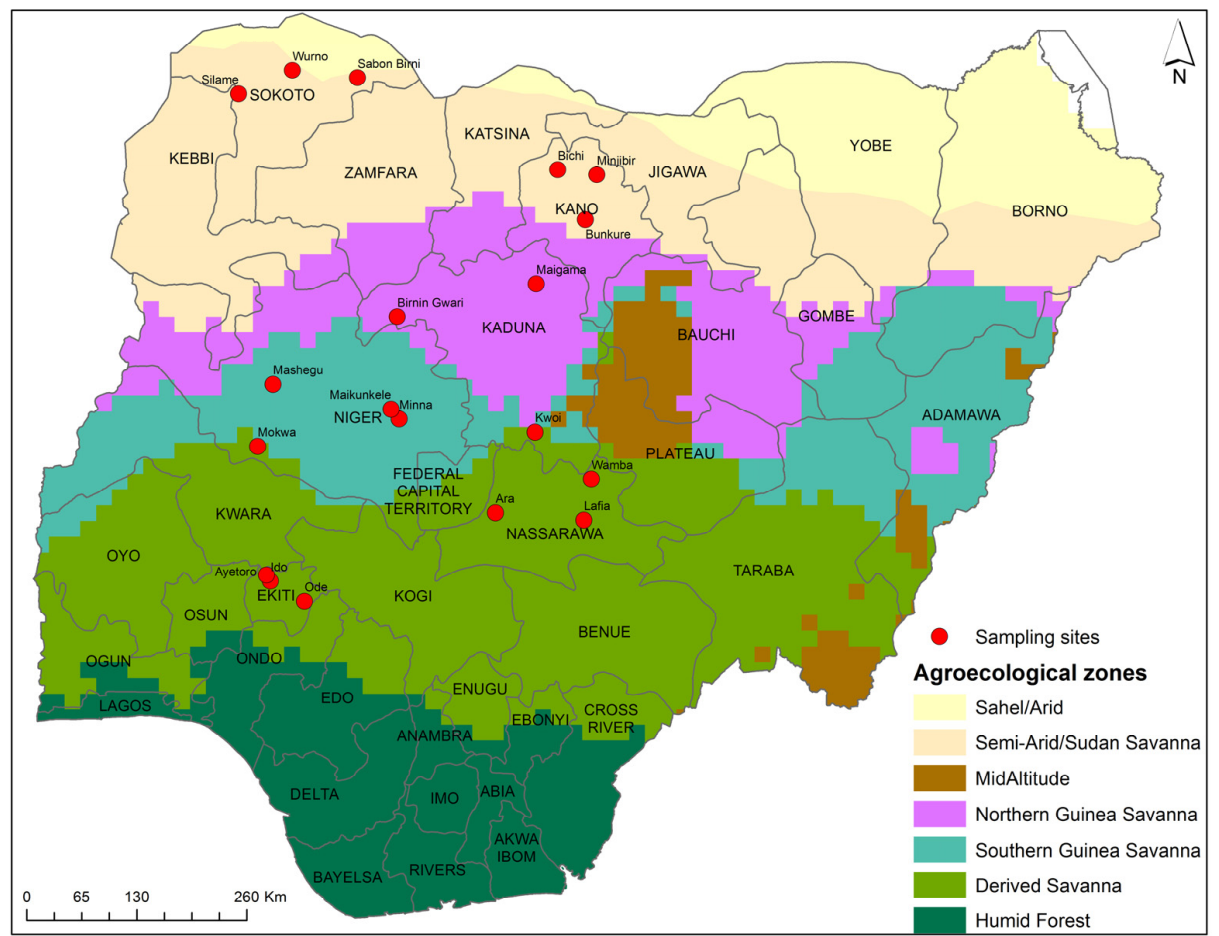

Figure 3. Map of Nigeria showing the sampling sites of maize, sorghum, millet, and ogi.

Table 4. Sampling sites of maize, sorghum, millet, and ogi from different agro-ecological zones of Nigeria.

\begin{tabular}{ccccc}
\hline Product Type & AEZ & State & No. of Markets & No. of Samples \\
\hline \multirow{5}{*}{ Maize } & SS & Kano & 6 & 30 \\
& NGS & Kaduna & 6 & 36 \\
& SGS & Niger & 8 & 40 \\
& DS & Nasarawa & 6 & 30 \\
& & & Total number $=136$ \\
\hline \multirow{3}{*}{ Sorghum } & SS & Kano & 6 & 30 \\
& NGS & Kaduna & 2 & 40 \\
& SGS & Niger & 8 & 40 \\
& & & & Total number $=110$ \\
\hline \multirow{3}{*}{ Millet } & SS & Sokoto & 6 & 30 \\
& NGS & Kaduna & 6 & 27 \\
& SGS & Niger & 8 & Total number $=87$ \\
\hline \multirow{2}{*}{ Ogi } & DS & Ekiti & 5 & Total number $=30$ \\
\hline
\end{tabular}

Abbreviation: AEZ = agro-ecological zones, SS = Sudan Savanna, NGS = Northern Guinea Savanna, SGS = Southern Guinea Savanna, DS = Derived Savanna. 
A total of 363 samples comprising of maize (Zea mays) $(n=136)$, sorghum (Sorghum bicolor) ( $n=110)$, millet (Pennisetum glaucum) $(n=87)$, and ogi $(n=30)$ were collected from randomly selected markets between September 2015 and October 2015. All cereal samples were sorted and cleaned and had no visible mould before going to the market. Sampling was carried out as described by Adetunji et al. and European Commission Regulation with some modifications [32,64]. Briefly, the whole content of a traditional bag of $50 \mathrm{~kg}$ of maize, sorghum, and millet was considered as a lot. An aggregate sample size of $1 \mathrm{~kg}$ was composed of 5 incremental samples. Each incremental portion was about $200 \mathrm{~g}$, and one was taken from different positions in the bag. In the case of ogi, $300 \mathrm{~g}$ of sample was collected from the top, middle, and bottom portions of the jute sack of $10 \mathrm{~kg}$ ogi, thoroughly mixed together, air dried, and packed in a plastic container. Each sample of the different food products (maize, sorghum, millet, and ogi) was thoroughly homogenised, and a representative portion of $200 \mathrm{~g}$ was taken, labelled, and sealed in zip lock bags, and transported to the Laboratory of Food Analysis, Ghent University, Belgium (Ottergemsesteenweg 460, Ghent, Belgium) for further analysis. Prior to analysis, maize, sorghum, millet, and ogi samples were milled to a sieve size of $0.5-1 \mathrm{~mm}$ using an IKA M20 universal mill (Sigma-Aldrich, Bornem, Belgium) and stored at $-20^{\circ} \mathrm{C}$.

\subsection{Chemicals and Reagents}

Methanol (MeOH, LC-MS grade), glacial acetic acid (LC-MS grade), and analytical grade acetonitrile were purchased from Biosolve B.V. (Valkenswaard, The Netherlands). Analytical grade acetic acid, ammonium acetate and sodium chloride were obtained from Merck (Darmstadt, Germany). Analytical grade of $\mathrm{n}$-hexane and methanol, Whatman ${ }^{\circledR}$ glass microfiber filters (GFA, $47 \mathrm{~mm}$ diameter) were purchased from VWR International (Zaventem, Belgium). Ultrafree ${ }^{\circledR}$-MC centrifugal filter devices $(0.22 \mu \mathrm{m})$ were obtained from Millipore (Bredford, MA, USA). C18 solid phase extraction (SPE) columns and MultiSep ${ }^{\circledR} 226$ AflaZon+ multifunctional columns were purchased from Alltech (Lokeren, Belgium) and Romer Labs (Gernsheim, Germany), respectively. Water was purified using a Milli-Q Gradient System (Millipore; Brussels, Belgium). All other chemicals and reagents used were of analytical grade.

The analytical mycotoxin standards including $\mathrm{FB}_{1}, \mathrm{FB}_{2}, \mathrm{DON}, 3 \mathrm{ADON}, 15 \mathrm{ADON}$, deepoxydeoxynivalenol (DOM), FUS-X, NIV, HT-2, NEO, ZEN, zearalanone (ZAN), $\alpha$-ZEL, $\beta$-ZEL were purchased from Sigma-Aldrich (Bornem, Belgium). $\mathrm{FB}_{3}$ was obtained from Promec Unit (Tygerberg, South Africa). DAS, DON-3G and T-2 were purchased from Biopure Referenzsubstanze (Tulln, Austria) while ZEN-14G was synthesized via an in-house validated method according to Zill et al. [65]. Stock solutions of $\mathrm{FB}_{1}, \mathrm{FB}_{2}, \mathrm{FB}_{3}$, DON, 3-ADON, 15-ADON, HT-2, T-2, ZEN, ZAN, $\alpha$-ZEL, $\beta$-ZEL, FUS-X, NIV, NEO, and DAS were prepared in $\mathrm{MeOH}$ at a concentration of $1 \mathrm{mg} / \mathrm{mL}$. DOM $(50 \mu \mathrm{g} / \mathrm{mL})$, DON-3G $(50.2 \mu \mathrm{g} / \mathrm{mL})$ and ZEN-14G $(100 \mu \mathrm{g} / \mathrm{mL})$ were obtained as solution in acetonitrile. All stock solutions were stored for 1 year or until the expiration date at $-18{ }^{\circ} \mathrm{C}$. The working standard solutions were made by diluting the stock standard solutions in methanol, and were stored at $-18{ }^{\circ} \mathrm{C}$ for 3 months. From the individual stock and working standard solutions, a standard mixture was prepared in methanol at the following concentrations: $\mathrm{FB}_{1}, \mathrm{FB}_{2}$, and $\mathrm{DON}(40 \mathrm{ng} / \mu \mathrm{L}), \mathrm{FB}_{3}(25 \mathrm{ng} / \mu \mathrm{L})$, 3-ADON (5 ng/ $\mu \mathrm{L}), 15-\mathrm{ADON}(2.5 \mathrm{ng} / \mu \mathrm{L}), \mathrm{HT}-2, \mathrm{~T}-2, \mathrm{ZEN}, \alpha$-ZEL, $\beta$-ZEL, ZEN-14G, DON-3G, and NEO $(10 \mathrm{ng} / \mu \mathrm{L})$, FUS-X and NIV $(20 \mathrm{ng} / \mu \mathrm{L})$, and DAS $(0.5 \mathrm{ng} / \mu \mathrm{L})$. The mixture was stored at $-18^{\circ} \mathrm{C}$, and renewed every 3 months.

\subsection{Sample Extraction}

Sample preparation for 17 Fusarium mycotoxins was carried out as described by Monbaliu et al. [66] for multi-mycotoxin analysis. Briefly, $5 \mathrm{~g}$ of sample was spiked with internal standards (ZAN and DOM at a concentration of 250 and $150 \mu \mathrm{g} / \mathrm{kg}$, respectively). DOM was used as internal standard for DON, DON-3G, 3ADON, and 15ADON while ZAN was used for the other mycotoxins. Spiked sample was kept in the dark for $15 \mathrm{~min}$ and extracted with acetonitrile/water/acetic acid (79/20/1, $v / v / v$ ). The supernatant was passed through a preconditioned C18-SPE column, and the extract was 
defatted. In order to recover the 17 Fusarium mycotoxins, two clean-up pathways were followed. Firstly, $12.5 \mathrm{~mL}$ of the defatted extract was added to $27.5 \mathrm{~mL}$ of acetonitrile/acetic acid $(99 / 1, v / v)$, and passed through a MultiSep ${ }^{\circledR} 226$ AflaZon+ multifunctional column. In the second pathway, $10 \mathrm{~mL}$ of defatted extract was filtered using a glass microfilter. Two milliliters of the filtered extract were combined with the Multisep226 eluate and evaporated to dryness. The residue was then redissolved in $150 \mu \mathrm{L}$ of the mobile phase (water/methanol/acetic acid $(94 / 5 / 1, v / v / v)+5 \mathrm{mM}$ ammonium acetate and water/methanol/acetic acid $(2 / 97 / 1, v / v / v)+5 \mathrm{mM}$ ammonium acetate in the ratio of 3/2, v/v). The redisolved mixture was then filtered using the Ultrafree ${ }^{\circledR}$ PVDF centrifuge filters and analysed by LC-MS/MS.

\subsection{Preparation of the Hydrolysed $F B_{1}, F B_{2}$, and $F B_{3}$ Standard}

The hydrolysed FB standards were prepared as described by Dall Asta et al. [24]. Briefly, $90 \mu \mathrm{L}$ standard solution of $\mathrm{FB}_{1}, \mathrm{FB}_{2}$, and $\mathrm{FB}_{3}(50 \mu \mathrm{g} / \mathrm{mL}$ of each) was prepared in methanol, transferred to a $10 \mathrm{~mL}$ sovirel tube, and evaporated to dryness under a gentle stream of nitrogen. The residue was redissolved in $2 \mathrm{M} \mathrm{NaOH}(1 \mathrm{~mL})$, and the reaction was incubated overnight at room temperature. After hydrolysis, the mixture was extracted by liquid-liquid partition using acetonitrile $(1 \mathrm{~mL})$. The extraction was repeated two more times using $1 \mathrm{~mL}$ fresh acetonitrile. The organic phases were pooled together, evaporated under a nitrogen stream and redissolved in $1 \mathrm{~mL}$ of methanol. The reaction yield was checked by LC-MS, by monitoring the conversion of FB to hydrolysed FB and the absence of side-products, and it was found to be higher than $99 \%$. Calibration curves were prepared by proper dilution of the standard solution, assuming the total conversion of the native compounds to the hydrolysed forms.

\subsection{Sample Preparation for Hydrolysed Fumonisins}

Ten samples from each matrix were selected for analysis of hydrolysed fumonisin; five samples comprising of high FB contaminated samples, while the second five samples were comprised of negative samples. Sample preparation was carried out as described by Dall Asta et al. [24]. Two and half grams of each sample was weighed, and was hydrolysed at room temperature using $50 \mathrm{~mL}$ of $2 \mathrm{M} \mathrm{NaOH}$, homogenised with the Ultraturrax for $3 \mathrm{~min}$, and then stirred using a magnetic stirrer for $60 \mathrm{~min}$. Subsequently, $50 \mathrm{~mL}$ of acetonitrile was added, and homogenised for $3 \mathrm{~min}$, and $20 \mathrm{~mL}$ of the upper organic phase was transferred into a centrifuge tube, and centrifuged for $15 \mathrm{~min}$ at $3500 \mathrm{rpm}$. Then, $4 \mathrm{~mL}$ was evaporated, and the residue was redissolved in $1 \mathrm{~mL}$ of water/methanol $(30 / 70, v / v)$, and analysed by LC-MS/MS.

\subsection{Liquid Chromatography-Tandem Mass Spectrometry}

A Waters Acquity UPLC system coupled to a Micromass Quattro Micro triple-quadrupole mass spectrometer (Waters, Milford, MA, USA) was used for the detection and quantification of mycotoxins in the samples. The data acquisition and processing utilities included the use of the MassLynx ${ }^{\mathrm{TM}}$ version 4.1 and QuanLynx ${ }^{\circledR}$ version 4.1 software (Micromass, Manchester, UK). The column used was a Symmetry C18 $(150 \mathrm{~mm} \times 2.1 \mathrm{~mm}$ i.d. $5 \mu \mathrm{m})$ column with a guard column $(10 \mathrm{~mm} \times 2.1 \mathrm{~mm}$ i.d.) of the same material (Waters, Zellik, Belgium), and was kept at room temperature. The injection volume was $20 \mu \mathrm{L}$. Mobile phase consisting of water/methanol/acetic acid (94/5/1, v/v/v) and $5 \mathrm{mM}$ ammonium acetate (mobile phase A), and methanol/water/acetic acid $(97 / 2 / 1, v / v / v)$ and $5 \mathrm{mM}$ ammonium acetate (mobile phase B) were used at a flow rate of $0.3 \mathrm{~mL} / \mathrm{min}$ with a gradient elution program. The gradient started at $95 \%$ mobile phase A with a linear decrease to $35 \%$ in 7 min. Mobile phase A decreased to $25 \%$ at $4 \mathrm{~min}$, and an isocratic period of $100 \%$, mobile phase B started at $11 \mathrm{~min}$ for $2 \mathrm{~min}$. Initial column conditions were reached at $23 \mathrm{~min}$ using a linear decrease of mobile phase B, and the column was reconditioned for 5 min prior to the following injection. The mass spectrometer was operated using selected reaction monitoring (SRM) channels in positive electrospray ionization (ESI+) mode. More information and on the transition of the different mycotoxins are described by 
De Boevre et al. [41] and Monbaliu et al. [67]. The capillary voltage was $3.2 \mathrm{kV}$, and nitrogen was used as the desolvation gas. Source and desolvation temperatures were set at 150 and $350{ }^{\circ} \mathrm{C}$, respectively.

\subsection{Method Validation}

For each matrix, validation parameters including apparent recovery, limit of detection (LOD), limit of quantification (LOQ) and measurement uncertainty were evaluated. Five blank samples of each matrix were spiked in triplicate with the different mycotoxins $\left(\mathrm{FB}_{1}, \mathrm{FB}_{2}\right.$ and $\mathrm{FB}_{3}, \mathrm{ZEN}, \alpha-\mathrm{ZEL}$, $\beta$-ZEL, ZEN-14G, DON, 3ADON, 15ADON, DON-3G, NIV, FUS-X, T-2, HT-2, DAS, NEO) on three different days at concentration levels shown on Table S1. ZAN and DOM were added as internal standards (IS). Matrix-matched calibration (MMC) plots were constructed by applying the least-squares method, and by plotting the relative peak area (peak area of toxin/peak area of IS) against the spiked concentration level of the sample. The linearity was evaluated graphically using a scatter plot, and the linear regression model was tested using a lack-of-fit test. The apparent recovery for each of the mycotoxins was evaluated by dividing the observed value from the MMC curves by the spiked level. The obtained results ranged between $75 \%$ and $110 \%$, which is in conformity with the range set in legislation [64].

A precision study with regards to repeatability (intraday precision) and reproducibility (interday precision) within laboratory was performed using five concentration levels, and was calculated using relative standard deviation (RSD). The results are presented in Table S1. LOD and LOQ for individual mycotoxins were obtained from the signal-to-noise $(\mathrm{S} / \mathrm{N})$ ratio which have been defined and set as 3 and 10, respectively, by the International Union of Pure and Applied Chemistry (IUPAC). The LOQs of individual mycotoxins in maize, sorghum, and millet are shown in Table S2.

\subsection{Statistical Analysis}

Data were processed and calculated using Microsoft office Excel 2007 (Redmond, WA, USA) and the statistical package R version 3.0.3 (The R Foundation for Statistical Computing, Vienna, Austria). The Kruskal Wallis statistical test (an alternative to one-way analysis of variance (ANOVA) under nonparametric test) was used to assess the significance of the differences between the determined mycotoxin concentrations and the different AEZ.

Supplementary Materials: The following are available online at www.mdpi.com/2072-6651/8/11/342/s1, Table S1: Intraday repeatability (RSDr, \%) and interday reproducibility (RSDR, \%) (within laboratory) of the individual mycotoxins for maize, sorghum and millet. Table S2: Limits of detection (LOD, $\mu \mathrm{g} / \mathrm{kg}$ ) and limits of quantification $(\mathrm{LOQ}, \mu \mathrm{g} / \mathrm{kg}$ ) of the individual mycotoxins for maize, sorghum, and millet.

Acknowledgments: The authors would like to thank Ghent University Special Research Fund (BOF 01W01014) for the financial support.

Author Contributions: C.A.C. designed the experiments, performed the sampling survey and the experiments. C.A.C. prepared the manuscript. M.D.B., O.O.A. and S.D.S. supervised the research, edited and approved the final manuscript.

Conflicts of Interest: The authors declare no conflict of interest.

\section{References}

1. Bennett, J.W.; Klich, M. Mycotoxins. Clin. Microbiol. Rev. 2003, 16, 497-516. [CrossRef] [PubMed]

2. Council for Agricultural Science and Technology (CAST). Mycotoxins: Risks in Plant, Animal, and Human Systems; Task force Report No. 139; Council for Agricultural Science and Technology: Ames, IA, USA, 2003.

3. Yazar, S.; Omurtag, G.Z. Fumonisins, trichothecenes and zearalenone in cereals. Int. J. Mol. Sci. 2008, 9, 2062-2090. [CrossRef] [PubMed]

4. International Agency for Research on Cancer (IARC). IARC monographs on the evaluation of carcinogenic risk to humans. IARC 1993, 56, 1-521. 
5. De Boevre, M.; Di Mavungu, J.D.; Landschoot, S.; Audenaert, K.; Eeckhout, M.; Maene, P.; Haesaert, G.; De Saeger, S. Natural occurrence of mycotoxins and their masked forms in food and feed products. World Mycotoxin J. 2012, 5, 207-219. [CrossRef]

6. Rodriguez-Carrasco, Y.; Fattore, M.; Albrizio, S.; Berrada, H.; Manes, J. Occurrence of Fusarium mycotoxins and their dietary intake through beer consumption by the European population. Food Chem. 2015, 178, 149-155. [CrossRef] [PubMed]

7. De Angelis, E.; Monaci, L.; Pascale, M.; Visconti, A. Fate of deoxynivalenol, T-2 and HT-2 toxins and their glucoside conjugates from flour to bread: An investigation by high-performance liquid chromatography high-resolution mass spectrometry. Food Addit. Contam. Part A 2012, 30, 345-355. [CrossRef] [PubMed]

8. Stanciu, O.; Juan, C.; Miere, D.; Loghin, F.; Mañes, J. Occurrence and co-occurrence of Fusarium mycotoxins in wheat grains and wheat flour from Romania. Food Control 2016, in press. [CrossRef]

9. Speijers, G.J.A.; Speijers, M.H.M. Combined toxic effects of mycotoxins. Toxicol. Lett. 2004, 153, 91-98. [CrossRef] [PubMed]

10. Kouadio, J.H.; Dano, S.D.; Moukha, S.; Mobio, T.A.; Creppy, E.E. Effects of combinations of Fusarium mycotoxins on the inhibition of macromolecular synthesis, malondialdehyde levels, $\{$ DNA $\}$ methylation and fragmentation, and viability in Caco-2 cells. Toxicon 2007, 49, 306-317. [CrossRef] [PubMed]

11. Alassane-Kpembi, I.; Kolf-Clauw, M.; Gauthier, T.; Abrami, R.; Abiola, F.A.; Oswald, I.P.; Puel, O. New insights into mycotoxin mixtures: The toxicity of low doses of Type B trichothecenes on intestinal epithelial cells is synergistic. Toxicol. Appl. Pharmacol. 2013, 272, 191-198. [CrossRef] [PubMed]

12. Luongo, D.; De Luna, R.; Russo, R.; Severino, L. Effects of four Fusarium toxins (fumonisin B ${ }_{1}, \alpha$-zearalenol, nivalenol and deoxynivalenol) on porcine whole-blood cellular proliferation. Toxicon 2008, 52, 156-162. [CrossRef] [PubMed]

13. Harvey, R.B.; Edrington, T.S.; Kubena, L.F.; Elissalde, M.H.; Casper, H.H.; Rottinghaus, G.E.; Turk, J.R. Effects of dietary fumonisin $\mathrm{B}_{1}$-containing culture material, deoxynivalenol-contaminated wheat, or their combination on growing barrows. Am. J. Vet. Res. 1996, 57, 1790-1794. [PubMed]

14. Kubena, L.F.; Edrington, T.S.; Harvey, R.B.; Phillips, T.D.; Sarr, A.B.; Rottinghaus, G.E. Individual and combined effects of fumonisin $\mathrm{B}_{1}$ present in Fusarium moniliforme culture material and diacetoxyscirpenol or ochratoxin A in turkey poults. Poult. Sci. 1997, 76, 256-264. [CrossRef] [PubMed]

15. Alassane-Kpembi, I.; Puel, O.; Oswald, I.P. Toxicological interactions between the mycotoxins deoxynivalenol, nivalenol and their acetylated derivatives in intestinal epithelial cells. Arch. Toxicol. 2015, 89, 1337-1346. [CrossRef] [PubMed]

16. Rychlik, M.; Humpf, H.U.; Marko, D.; Dänicke, S.; Mally, A.; Berthiller, F.; Klaffke, H.; Lorenz, N. Proposal of a comprehensive definition of modified and other forms of mycotoxins including "masked" mycotoxins. Mycotoxin Res. 2014, 30, 197-205. [CrossRef] [PubMed]

17. Berthiller, F.; Crews, C.; Dall'Asta, C.; De Saeger, S.; Haesaert, G.; Karlovsky, P.; Oswald, I.P.; Seefelder, W.; Speijers, G.; Stroka, J. Masked mycotoxins: A review. Mol. Nutr. Food Res. 2013, 57, 165-186. [CrossRef] [PubMed]

18. Broekaert, N.; Devreese, M.; De Baere, S.; De Backer, P.; Croubels, S. Modified Fusarium mycotoxins unmasked: From occurrence in cereals to animal and human excretion. Food Chem. Toxicol. 2015, 80, 17-31. [CrossRef] [PubMed]

19. De Boevre, M; Jacxsens, L.; Lachat, C.; Eeckhout, M.; Di Mavungu, D.M.; Audenaert, K.; Maene, P.; Haesaert, G.; Kolsteren, P.; De Meulenaer, B.; et al. Human exposure to mycotoxins and their masked forms through cereal-based foods in Belgium. Toxicol. Lett. 2013, 218, 281-292. [CrossRef] [PubMed]

20. Oliveira, M.S.; Diel, A.C.L.; Rauber, R.H.; Fontoura, F.P.; Mallmann, A.; Dilkin, P.; Mallmann, C.A. Free and hidden fumonisins in Brazilian raw maize samples. Food Control 2015, 53, 217-221. [CrossRef]

21. Dall'Asta, C.; Galaverna, G.; Mangia, M.; Sforza, S.; Dossena, A.; Marchelli, R. Free and bound fumonisins in gluten-free food products. Mol. Nutr. Food Res. 2009, 53, 492-499. [CrossRef] [PubMed]

22. Dall'Asta, C.; Mangia, M.; Berthiller, F.; Molinelli, A.; Sulyok, M.; Schuhmacher, R.; Krska, R.; Galaverna, G.; Dossena, A.; Marchelli, R. Difficulties in fumonisin determination: The issue of hidden fumonisins. Anal. Bioanal. Chem. 2009, 395, 1335-1345. [CrossRef] [PubMed]

23. Galaverna, G.; Dallsta, C.; Mangia, M.A.; Dossena, A.; Marchelli, R. Masked mycotoxins: An emerging issue for food safety. Czech J. Food Sci. 2009, 27, 89-92. 
24. Dall'Asta, C.; Galaverna, G.; Aureli, G.; Dossena, A.; Marchelli, R. A LC/MS/MS method for the simultaneous quantification of free and masked fumonisins in maize and maize-based products. World Mycotoxin J. 2008, 1, 237-246. [CrossRef]

25. Ezekiel, C.N.; Odebode, A.C.; Fapohunda, S.O. Zearalenone production by naturally occurring Fusarium species on maize, wheat and soybeans from Nigeria. J. Biol. Environ. Sci. 2008, 2, 77-82.

26. Adejumo, T.O.; Hettwer, U.; Karlovsky, P. Occurrence of Fusarium species and trichothecenes in Nigerian maize. Int. J. Food Microbiol. 2007, 116, 350-357. [CrossRef] [PubMed]

27. European Commission (EC). Comission regulation (EC) No 1126/2007 of 28 September 2007 amending Regulation (EC) No 1881/2006 setting maximum levels for certain contaminants in foodstuffs as regards Fusarium toxins in maize and maize products. Off. J. Eur. Union 2007, L 255, 14-17.

28. Kpodo, K.; Thrane, U.; Hald, B. Fusaria and fumonisins in maize from Ghana and their co-occurrence with aflatoxins. Int. J. Food Microbiol. 2000, 61, 147-157. [CrossRef]

29. Warth, B.; Parich, A.; Atehnkeng, J.; Bandyopadhyay, R.; Schuhmacher, R.; Sulyok, M.; Krska, R. Quantitation of mycotoxins in food and feed from burkina faso and mozambique using a modern LC-MS/MS multitoxin method. J. Agric. Food Chem. 2012, 60, 9352-9363. [CrossRef] [PubMed]

30. Phoku, J.Z.; Dutton, M.F.; Njobeh, P.B.; Mwanza, M.; Egbuta, M.A.; Chilaka, C.A. Fusarium infection of maize and maize-based products and exposure of a rural population to fumonisin $\mathrm{B}_{1}$ in Limpopo Province, South Africa. Food Addit. Contam. Part A Chem. Anal. Control Expo. Risk Assess. 2012, 29, 1743-1751. [CrossRef] [PubMed]

31. Abia, W.A.; Warth, B.; Sulyok, M.; Krska, R.; Tchana, A.N.; Njobeh, P.B.; Dutton, M.F.; Moundipa, P.F. Determination of multi-mycotoxin occurrence in cereals, nuts and their products in Cameroon by liquid chromatography tandem mass spectrometry (LC-MS/MS). Food Control 2013, 31, 438-453. [CrossRef]

32. Adetunji, M.; Atanda, O.; Ezekiel, C.N.; Sulyok, M.; Warth, B.; Beltrán, E.; Krska, R.; Obadina, O.; Bakare, A.; Chilaka, C.A. Fungal and bacterial metabolites of stored maize (Zea mays, L.) from five agro-ecological zones of Nigeria. Mycotoxin Res. 2014, 30, 89-102. [CrossRef] [PubMed]

33. Peters, J.; Thomas, D.; Boers, E.; De Rijk, T.; Berthiller, F.; Haasnoot, W.; Nielen, M.W.F. Colour-encoded paramagnetic microbead-based direct inhibition triplex flow cytometric immunoassay for ochratoxin A, fumonisins and zearalenone in cereals and cereal-based feed rapid detection in food and feed. Anal. Bioanal. Chem. 2013, 405, 7783-7794. [CrossRef] [PubMed]

34. Ediage, E.N.; Hell, K.; De Saeger, S. A comprehensive study to explore differences in mycotoxin patterns from agro-ecological regions through maize, peanut, and cassava products: A case study, cameroon. J. Agric. Food Chem. 2014, 62, 4789-4797. [CrossRef] [PubMed]

35. Chilaka, C.A.; de Kock, S.; Phoku, J.Z.; Mwanza, M.; Egbuta, M.A.; Dutton, M.F. Fungal and mycotoxin contamination of South African commercial maize. J. Food Agric. Environ. 2012, 10, 296-303.

36. Chala, A.; Taye, W.; Ayalew, A.; Krska, R.; Sulyok, M.; Logrieco, A. Multimycotoxin analysis of sorghum (Sorghum bicolor L. Moench) and finger millet (Eleusine coracana L. Garten) from Ethiopia. Food Control 2014, 45, 29-35. [CrossRef]

37. Ayalew, A.; Fehrmann, H.; Lepschy, J.; Beck, R.; Abate, D. Natural occurrence of mycotoxins in staple cereals from Ethiopia. Mycopathologia 2006, 162, 57-63. [CrossRef] [PubMed]

38. Soares, C.; Calado, T.; Venâncio, A. Mycotoxin production by Aspergillus niger aggregate isolated from harvested maize in three Portuguese regions. Rev. Iberoam. Micol. 2012, 30, 9-13. [CrossRef] [PubMed]

39. Ezekiel, C.N.; Abia, W.A.; Ogara, I.M.; Sulyok, M.; Warth, B.; Krska, R. Fate of mycotoxins in two popular traditional cereal-based beverages (kunu-zaki and pito) from rural Nigeria. LWT Food Sci. Technol. 2015, 60, 137-141. [CrossRef]

40. Makun, H.A.; Dutton, M.F.; Njobeh, P.B.; Mwanza, M.; Kabiru, A.Y. Natural multi-occurrence of mycotoxins in rice from Niger State, Nigeria. Mycotoxin Res. 2011, 27, 97-104. [CrossRef] [PubMed]

41. De Boevre, M.; Di Mavungu, J.D.; Maene, P.; Audenaert, K.; Deforce, D.; Haesaert, G.; Eeckhout, M.; Callebaut, A.; Berthiller, F.; Van Peteghem, C.; et al. Development and validation of an LC-MS/MS method for the simultaneous determination of deoxynivalenol, zearalenone, T-2-toxin and some masked metabolites in different cereals and cereal-derived food. Food Addit. Contam. Part A 2012, 29, 819-835. [CrossRef] [PubMed] 
42. Mirocha, C.J.; Abbas, H.K.; Windels, C.E.; Xie, W. Variation in deoxynivalenol, 15-acetyldeoxynivalenol, 3-acetyldeoxynivalenol, and zearalenone production by Fusarium graminearum isolates. Appl. Environ. Microbiol. 1989, 55, 1315-1316. [PubMed]

43. Abedi-tizaki, M.; Sabbagh, S. Detection of 3-Acetyldeoxynivalenol, 15-Acetyldeoxynivalenol and Nivalenol-Chemotypes of Fusarium graminearum from Iran using specific PCR assays a b c d. Plant Knowl. J. 2013, 2, 38-42.

44. Li, H.-P.; Wu, A.-B.; Zhao, C.-S.; Scholten, O.; Löffler, H.; Liao, Y.-C. Development of a generic PCR detection of deoxynivalenol- and nivalenol-chemotypes of Fusarium graminearum. FEMS Microbiol. Lett. 2005, 243, 505-511. [CrossRef] [PubMed]

45. Castillo, M.-Á.; Montes, R.; Navarro, A.; Segarra, R.; Cuesta, G.; Hernández, E. Occurrence of deoxynivalenol and nivalenol in Spanish corn-based food products. J. Food Compos. Anal. 2008, 21, 423-427. [CrossRef]

46. Gottschalk, C.; Barthel, J.; Engelhardt, G.; Bauer, J.; Meyer, K. Simultaneous determination of type A, B and D trichothecenes and their occurrence in cereals and cereal products. Food Addit. Contam. 2009, 26, 1273-1289. [CrossRef]

47. Sokolović, M.; Šimpraga, B. Survey of trichothecene mycotoxins in grains and animal feed in Croatia by thin layer chromatography. Food Control 2006, 17, 733-740. [CrossRef]

48. European Commission (EC). Commission recomendations on the presence of T-2 and HT-2 toxin in cereals and cereal products. Off. J. Eur. Union 2013, 56, 12-15.

49. Adejumo, T.O.; Hettwer, U.; Karlovsky, P. Survey of maize from south-western Nigeria for zearalenone, $\alpha$ - and $\beta$-zearalenols, fumonisin $B_{1}$ and enniatins produced by Fusarium species. Food Addit. Contam. 2007, 24, 993-1000. [CrossRef] [PubMed]

50. European Commission (EC). Commission regulation (EC) No 1881/2006 Setting maximum levels for certain contaminants in foodstuffs. Off. J. Eur. Union 2006, L 364/5, 1-26.

51. De Boevre, M.; Graniczkowska, K.; De Saeger, S. Metabolism of modified mycotoxins studied through in vitro and in vivo models: An overview. Toxicol. Lett. 2015, 233, 24-28. [CrossRef] [PubMed]

52. Park, J.W.; Scott, P.M.; Lau, B.P.-Y.; Lewis, D.A. Analysis of heat-processed corn foods for fumonisins and bound fumonisins. Food Addit. Contam. 2004, 21, 1168-1178. [CrossRef] [PubMed]

53. Kim, E.K.; Scott, P.M.; Lau, B.P.Y. Hidden fumonisin in corn flakes. Food Addit.Contam. 2003, 20, 161-169. [CrossRef] [PubMed]

54. Dall'Asta, C.; Falavigna, C.; Galaverna, G.; Dossena, A.; Marchelli, R. In vitro digestion assay for determination of hidden fumonisins in maize. J. Agric. Food Chem. 2010, 58, 12042-12047. [CrossRef] [PubMed]

55. Shier, W.T. The fumonisin paradox: A review of research on oral bioavailability of fumonisin $\mathrm{B}_{1}$, a mycotoxin produced by Fusarium moniliforme. J. Toxicol. Toxin Rev. 2000, 19, 161-187. [CrossRef]

56. Shephard, G.S.; Thiel, P.G.; Stockenstrom, S.; Sydenham, E.W. Worldwide survey of fumonisin concentration of corn and corn-based foods. J. AOAC Int. 1996, 79, 671-687. [PubMed]

57. Femine Early Warning Systems Network (FEWS NET). Visualizing Trends in 1981-2015 Rainfall in Nigeria. Nigeria Special Report. Available online: www.fews.net/sites/default/files/documents/reports / FEWSNET_NigeriaRainfallTrendsMapBook_20160601 (accessed on 28 September 2016).

58. Milani, J.M. Ecological conditions affecting mycotoxin production in cereals: A review. Vet. Med. (Praha) 2013, 58, 405-411.

59. Bottalico, A. Fusarium diseases of cereals: Species complex and related mycotoxin profiles in Europe. J. Plant Pathol. 1998, 80, 85-103.

60. Kim, D.-H.; Yoon, B.R.; Jeon, M.-H.; Kim, B.-C.; Cho, B.-I.; Hong, S.-Y.; Hyun, C.S. Simultaneous Determination of Multi-mycotoxins in Cereal Grains by LC-MS/MS. In International Association for Food Protection; IAFP: Portland, OR, USA, 2015; pp. P2-P65.

61. Okeke, C.A.; Ezekiel, C.N.; Nwangburuka, C.C.; Sulyok, M.; Ezeamagu, C.O.; Adeleke, R.A.; Dike, S.K.; Krska, R. Bacterial diversity and mycotoxin reduction during maize fermentation (steeping) for Ogi production. Front. Microbiol. 2015, 6, 1-12. [CrossRef] [PubMed]

62. Udoh, J.M.; Cardwell, K.F.; Ikotun, T. Storage structures and aflatoxin content of maize in five agroecological zones of Nigeria. J. Stored Prod. Res. 2000, 36, 187-201. [CrossRef] 
63. Atehnkeng, J.; Ojiambo, P.S.; Donner, M.; Ikotun, T.; Sikora, R.A.; Cotty, P.J.; Bandyopadhyay, R. Distribution and toxigenicity of Aspergillus species isolated from maize kernels from three agro-ecological zones in Nigeria. Int. J. Food Microbiol. 2008, 122, 74-84. [CrossRef] [PubMed]

64. European Commission (EC). Commission regulation (EC) No 401/2006 of 23 February 2006 laying down the methods of sampling and analysis for the official control of the levels of mycotoxins in foodstuffs. Off. J. Eur. Union 2006, L70, 12-34.

65. Zill, G.; Ziegler, W.; Engelhardt, G.; Wallnöfer, P.R. Chemically and biologically synthesized zearalenone4- $\beta$-d-glucopyranoside: Comparison and convenient determination by gradient HPLC. Chemosphere 1990, 21, 435-442. [CrossRef]

66. Sofie, M.; Van Poucke, C.; Detavernier, C.; Dumoultn, F.; Van Velde, M.D.E.; Schoeters, E.; Van Dyck, S.; Averkieva, O.; Van Peteghem, C.; De Saeger, S. Occurrence of mycotoxins in feed as analyzed by a multi-mycotoxin LC-MS/MS method. J. Agric. Food Chem. 2010, 58, 66-71.

67. Monbaliu, S.; Van Poucke, C.; Van Peteghem, C.; Van Poucke, K.; Heungens, K.; De Saeger, S. Development of a multi-mycotoxin liquid chromatography/tandem mass spectrometry method for sweet pepper analysis. Rapid Commun. Mass Spectrom. 2009, 23, 3-11. [CrossRef] [PubMed]

(C) 2016 by the authors; licensee MDPI, Basel, Switzerland. This article is an open access article distributed under the terms and conditions of the Creative Commons Attribution (CC-BY) license (http://creativecommons.org/licenses/by/4.0/). 